\title{
Impact of prenatal contraceptive counselling on immediate postpartum intrauterine device use
}

\author{
Renee T Sullender ${ }^{1}$, Amy L Godecker ${ }^{2}$, Emily R Rosen ${ }^{3}$ and Cynthia K Wautlet ${ }^{2 *}$ \\ ${ }^{1}$ Department of Obstetrics, Gynaecology, \& Reproductive Sciences, University of California at San Diego, San Diego, CA, USA \\ ${ }^{2}$ Department of Obstetrics and Gynaecology, University of Wisconsin School of Medicine and Public Health, Madison, Wisconsin, USA \\ ${ }^{3}$ Department of Obstetrics and Gynaecology, Ohio State University Wexner Medical Center, Columbus, Ohio, USA
}

\begin{abstract}
The American College of Obstetricians and Gynaecologists recommends that immediate postpartum intrauterine devices be offered as part of comprehensive family planning. Immediate postpartum intrauterine devices are not widely disseminated in clinical practice and little is known about how prenatal counselling strategies impact device use. Our objective was to examine the impact of variable prenatal counselling practices on device uptake. We conducted a retrospective case-control study of patients who obtained an immediate postpartum intrauterine device (cases, $\mathrm{n}=110$ ) at a major academic birthing facility over a three-year period. Controls $(n=205)$ had a live birth during the same period and received no or some other form of contraception before hospital discharge. We examined the timing and frequency of contraceptive counselling and used logistic regression to estimate odds ratios of device receipt adjusted for demographic and obstetric characteristics. $15 \%$ of cases and $36 \%$ of controls had no documentation that prenatal contraceptive counselling was offered or delivered ( $\mathrm{P}$ value <.001 (chi square test)). Cases had significantly more total documented counselling sessions (mean 2.6 vs 1.7 ; odds ratio 1.23 ; $95 \%$ confidence interval, 1.09-1.38) and more third trimester counselling (mean 2.24 vs. 1.36 ; odds ratio 1.33 ; $95 \%$ confidence interval, 1.16-1.53) compared to controls. Counselling on admission to the labor ward and provider type were not significant in adjusted models. When accompanied by outpatient prenatal counselling, those who received counselling on admission to the labor ward were five times more likely to receive a device. Given time constraints during prenatal visits, contraceptive counselling clustered in the third trimester followed by counselling on admission to the labor ward may be a reasonable way to offer immediate post-placental intrauterine devices. To promote reproductive autonomy and justice, comprehensive prenatal contraceptive counselling should be offered to all.
\end{abstract}

\section{Introduction}

Data from the National Survey of Family Growth indicates that $70 \%$ of pregnancies within the first postpartum year are unintended [1]. When conception occurs within 12 months of a prior delivery, risks of adverse pregnancy outcomes are elevated, including preterm deliveries, low birth weight infants, preterm rupture of membranes, utero-placental bleeding, and uterine scar rupture for those attempting a trial of labor after caesarean [2,3], yet the majority of people encounter barriers in accessing preferred postpartum contraception [4]. While the spectrum of pregnancy intendedness is fluid [5], healthcare providers play a critical role in ensuring reproductive health and autonomy by offering contraceptive counselling to all and ensuring each person is able to access their preferred, medically-appropriate method.

Immediate post-partum (IPP) intrauterine devices (IUD) are highly effective and associated with high continuation rates [6-8]. The American College of Obstetricians and Gynaecologists (ACOG) recommends counselling prenatally about the option of IPP IUD placement, defined as IUD placement with 10 minutes of placental delivery [9] and strongly encourages the practice of providing longacting reversible (LARC) methods, including IUDs and subdermal implants, in the postpartum period [10]. However, studies show that only half of individuals receive prenatal contraceptive counselling and even fewer (13\%) are counselled about LARC methods [11]. IPP IUDs are not widely disseminated in clinical practice and little is known about how prenatal counselling strategies impact use.

The objective of this study was to examine variable prenatal contraceptive counselling practices, including provider types and the initiation, timing, and frequency of prenatal counselling, among those who did and did not receive an IPP IUD at a major academic medical centre. We hypothesized that IPP IUD use would be associated with earlier and more prenatal contraceptive counselling.

\section{Materials and methods}

We conducted a retrospective case-control study examining the effect of prenatal contraceptive counselling on receipt of IPP IUDs. The study population included individuals with Medicaid insurance who had a live birth at Unity Point-Health Meriter Hospital in Madison, Wisconsin between November 2014 and March 2017. Cases included individuals with Medicaid who had a live birth at any gestational age during the study period, gave informed consent, and received an IPP IUD through the hospital's free LARC program. Cases were identified from LARC program logs where patient information was documented each time an IPP IUD was placed. Insertion was within 10 minutes of placental delivery for vaginal births and immediately after the delivery of the placenta for caesarean births. While the program specifically

${ }^{*}$ Correspondence to: Cynthia K Wautlet, Department of Obstetrics and Gynecology, University of Wisconsin School of Medicine and Public Health, 1102 South Park Street, Madison, Wisconsin, 53715, USA, Tel: +1 (608) 287-5807, Fax: +1 (608) 2512329; E-mail: cwautlet@wisc.edu

Key words: contraception, contraceptive counselling, intrauterine contraceptive device, long acting reversible contraception, prenatal care

Received: June 08, 2020; Accepted: June 30, 2020; Published: July 03, 2020 
offered LARC for free to Medicaid patients, all other forms of birth control were also available to them without cost.

Controls included those with Medicaid who had a live birth at any gestational age during the same time period who received any contraception other than an IPP IUD or no contraception before hospital discharge. We first identified all 2424 individuals with Medicaid coverage and a live birth during the study period and then randomly selected 209 with the goal of a 1:2 case: control allocation. Those who had an IUD placed at an outpatient postpartum visit were eligible to be controls. Those who underwent emergency hysterectomy were excluded as this was not considered a planned method of birth control. Those who had a fetal demise and were inadvertently included as controls were excluded from further analysis.

A systematic chart review was performed in the electronic health record (EHR, Epic) to abstract data on patient demographics, details about outpatient and inpatient prenatal contraceptive counselling, and postpartum contraceptive use for cases and controls.

The primary predictor (exposure) was prenatal contraceptive counselling as documented by any prenatal provider in outpatient and/ or inpatient EHR notes. We defined prenatal counselling as any time a patient encounter noted any discussion about birth control, from the first outpatient antenatal visit up to and including hospital admission. Counselling on hospital admission (identified from the admission note) was included separately from counselling at prenatal visits. Characteristics of contraceptive counselling included any prenatal counselling, weeks of gestation and trimester of first documented counselling, total number of prenatal counselling sessions, number of counselling sessions per trimester, counselling documented at hospital admission, and provider type at first prenatal counselling. Gestational age at counselling was measured in weeks; for instance, 13 weeks and 0 days through 13 weeks and 6 days were charted as " 13 weeks." Provider types included attending/fellow, resident, nurse practitioner, and midwife. Midwives in this practice counsel about and offer IPP LARC; if a midwifery patient chose an IPP IUD method it was placed by a resident.

Potential obstetric and demographic confounders were gestational age at delivery, maternal age at delivery, gravidity, parity (living), prior therapeutic abortion $(\mathrm{TAB})$, prior spontaneous abortion (SAB), delivery method, maternal race/ethnicity, and delivery year. TAB and SAB were abstracted directly from identically named EHR fields without further ability to classify these pregnancy outcomes. We used univariate logistic regression to calculate odds ratios, 95\% confidence intervals, and p-values. We used multivariable logistic regression to examine the odds ratio for contraceptive counselling adjusted for obstetric and demographic characteristics. For some models, we restricted logistic analyses to those who had any contraceptive counselling documented. Wald tests for equivalence of coefficients were used for selected models and the likelihood ratio test was used to assess relative model fit.

This study was deemed exempt by the Institutional Review Boards at the University of Wisconsin and UnityPoint-Health Meriter Hospital.

\section{Results}

During the study period, 110 individuals with Medicaid coverage received IPP IUDs through the University of Wisconsin LARC program and constituted the case population. The initial control population consisted of 209 individuals, four of whom were removed from the control group after further review: 1 received an IPP IUD,
1 was unable to be identified by chart review, 1 had an emergency postpartum hysterectomy for post-partum haemorrhage, and 1 patient had a pregnancy that ended in fetal demise. The final control population consisted of 205 patients.

There were no significant differences between the IPP IUD case vs. control groups in terms of obstetric and demographic characteristics (Table 1). Case and control groups were significantly different on several measures of contraceptive counselling (Table 2). Eighty-five percent of cases had documented prenatal contraceptive counselling (counselling at an outpatient antenatal visit) compared to $64 \%$ of controls (odds ratio (OR), 3.03; 95\% confidence interval (CI), 1.09-1.38). Gestational age at initial counselling was not statistically significant, even when the sample was restricted to those with any prenatal counselling or when examined by trimester.

Total number of prenatal counselling sessions and number of sessions for the third trimester were statistically significant. Cases had a significantly higher mean total number of counselling sessions (mean 2.6 vs. 1.7 ; OR, 1.23 ; 95\% CI, 1.09-1.38) (Table 2). The mean number of sessions was not significantly different for cases and controls for the first trimester (mean 0.21 vs. 0.18 ; OR, 1.04 ; $95 \% \mathrm{CI}, 0.84-1.29$ ) or second trimester (mean 0.96 vs 0.80 ; OR, 1.05; 95\% CI, 0.93-1.19), but cases had significantly more third trimester counselling sessions (mean 2.24 vs. 1.36; OR 1.33; 95\% CI 1.16-1.53). Although seventy-four percent of cases had counselling at hospital admission versus only $31 \%$ of controls (OR, 6.3, 95\% CI, 3.75-10.56), on further analysis counselling on admission was not significant unless this was accompanied by prenatal counselling (OR, 1.07; 95\% CI, 0.43-2.64).

Multivariable models adjusting for obstetric and demographic characteristics were consistent with unadjusted results for measures of counselling. The number of prenatal counselling sessions was significant, with each additional session increasing the odds of receiving an IPP IUD by $24 \%$ (OR, 1.24; 95\% CI, 1.09-1.41) (Table 3, Model 1). When prenatal counselling was subsequently evaluated by trimester (Table 3, Model 2), the number of counselling sessions in the third trimester was significant (OR, 1.43; 95\% CI, 1.21-1.70), but counts for first and second trimesters were not. Additionally, likelihood ratio test results showed that model fit was not significantly different when counts of first and second trimester counselling were omitted ( $\mathrm{p}=$ 0.41 , results not shown) and these characteristics of counselling were omitted from the remaining models. After adjusting for the number of contraceptive counselling sessions in the third trimester, model fit was significantly improved by inclusion of counselling on hospital admission, and those with counselling on admission had odds of receiving an IPP IUD 5 times higher than those who did not (OR, 5.10; 95\% CI, 2.01-9.71) (Table 3, Model 3). Examining the number of third trimester counselling sessions more closely, individuals who had 3 or more counselling sessions were more likely to have an IPP IUD placed than others with 0,1 , or 2 sessions. (Table 3 , Model 4 ).

In unadjusted models restricted to those who received any contraceptive counselling, patients whose first counselling was provided by a resident had significantly higher odds of receiving an IPP IUD than patients whose first counselling provider was a midwife (OR, 0.16; 95\% CI, 0.06-0.48) (Table 4). Residents also had a significantly higher mean number of counselling sessions documented. However, the difference between cases and controls by provider type was no longer significant after adjusting for demographic, obstetric, and other counselling characteristics. 
Table 1. Distribution and unadjusted* effect of obstetric and demographic characteristics of patients with and without immediate postpartum (IPP) intrauterine device (IUD) placement

\begin{tabular}{|c|c|c|c|c|c|c|c|}
\hline \multirow{3}{*}{$\begin{array}{l}\text { Characteristic } \\
\text { Gestational age (wks) at delivery, mean (SD) }\end{array}$} & \multirow{2}{*}{\multicolumn{2}{|c|}{$\begin{array}{c}\text { IPP IUD }(n=110) \\
\text { Case }\end{array}$}} & \multirow{2}{*}{\multicolumn{2}{|c|}{$\begin{array}{c}\text { Non-IPP IUD }(\mathbf{n}=\mathbf{2 0 5}) \\
\text { Control }\end{array}$}} & \multirow{3}{*}{$\begin{array}{l}\text { OR } \\
1.02\end{array}$} & \multirow{3}{*}{$\begin{array}{c}\mathbf{9 5 \%} \mathbf{C I} \\
0.92-1.13\end{array}$} & \multirow{3}{*}{$\begin{array}{c}\text { p-value } \\
0.66\end{array}$} \\
\hline & & & & & & & \\
\hline & 38.5 & $(1.83)$ & 38.4 & $(2.54)$ & & & \\
\hline Age (yrs) at delivery, mean (SD) & 26.5 & $(5.71)$ & 27.2 & $(5.70)$ & 0.98 & $0.94-1.02$ & 0.26 \\
\hline Gravidity, mean (SD) & 3.1 & $(1.98)$ & 2.9 & $(1.69)$ & 1.08 & $0.95-1.22$ & 0.26 \\
\hline Parity (living), mean (SD) & 1.4 & $(1.42)$ & 1.3 & $(1.46)$ & 1.05 & $0.90-1.24$ & 0.52 \\
\hline \multicolumn{8}{|l|}{ Previous therapeutic abortion, $\mathrm{n} \%$} \\
\hline No & 95 & 86.4 & 178 & 86.8 & \multicolumn{2}{|c|}{ (reference) } & \\
\hline Yes & 15 & 13.6 & 27 & 13.2 & 1.04 & $0.53-2.05$ & 0.91 \\
\hline \multicolumn{8}{|l|}{ Previous spontaneous abortion, $\mathrm{n} \%$} \\
\hline No & 71 & 64.6 & 154 & 75.1 & \multicolumn{2}{|c|}{ (reference) } & \\
\hline Yes & 39 & 35.5 & 51 & 24.9 & 1.66 & $1.00-2.74$ & 0.05 \\
\hline \multicolumn{8}{|l|}{ Delivery type, $\mathrm{n} \%$} \\
\hline C-Section & 40 & 36.4 & 55 & 26.8 & \multicolumn{2}{|c|}{ (reference) } & \\
\hline Vaginal & 70 & 63.6 & 150 & 73.2 & 0.64 & $0.39-1.05$ & 0.08 \\
\hline \multicolumn{8}{|l|}{ Race/ethnicity, n\% } \\
\hline White & 44 & 40.0 & 88 & 42.9 & \multicolumn{2}{|c|}{ (reference) } & \\
\hline Black & 39 & 35.5 & 51 & 24.9 & 1.53 & $0.88-2.66$ & 0.13 \\
\hline Hispanic/Latina & 22 & 20.0 & 45 & 22.0 & 0.98 & $0.52-1.83$ & 0.94 \\
\hline Other & 5 & 4.6 & 21 & 10.2 & 0.48 & $0.17-1.34$ & 0.16 \\
\hline \multicolumn{8}{|l|}{ Year of delivery, $\mathrm{n} \%$} \\
\hline 2014 (Nov-Dec) & 4 & 3.6 & 19 & 9.3 & 0.39 & $0.13-1.23$ & 0.11 \\
\hline 2015 (Jan-Dec) & 48 & 43.6 & 90 & 43.9 & \multicolumn{2}{|c|}{ (reference) } & \\
\hline 2016 (Jan-Dec) & 47 & 42.7 & 76 & 37.1 & 1.16 & $0.70-1.92$ & 0.57 \\
\hline 2017 (Jan-Mar) & 11 & 10.0 & 20 & 9.8 & 1.03 & $0.46-2.33$ & 0.94 \\
\hline
\end{tabular}

*Odds ratio, 95\% confidence interval (CI) and p-value results from unadjusted logistic regression predicting IPP IUD placement.

Table 2. Distribution and unadjusted* effects of characteristics of contraceptive counselling of patients with and without immediate postpartum (IPP) intrauterine device (IUD) placement

\begin{tabular}{|c|c|c|c|c|c|c|c|}
\hline \multirow{3}{*}{$\begin{array}{l}\text { Characteristic } \\
\text { Any prenatal counselling, } \mathrm{n} \%\end{array}$} & \multirow{2}{*}{\multicolumn{2}{|c|}{$\begin{array}{c}\text { IPP IUD }(\mathbf{n}=110) \\
\text { Case }\end{array}$}} & \multirow{2}{*}{\multicolumn{2}{|c|}{$\begin{array}{c}\text { Non-IPP-IUD }(\mathbf{n}=\mathbf{2 0 5}) \\
\text { Control }\end{array}$}} & \multirow{3}{*}{ OR } & \multirow{3}{*}{$95 \%$ CI } & \multirow[t]{3}{*}{ p-value } \\
\hline & & & & & & & \\
\hline & & & & & & & \\
\hline No & 17 & 15.5 & 73 & 35.6 & \multicolumn{2}{|c|}{ (reference) } & \\
\hline Yes & 93 & 84.6 & 132 & 64.4 & 3.03 & $1.68-5.46$ & 0.00 \\
\hline Weeks gestation at first counselling, mean, (SD) & 28.9 & $(7.22)$ & 27.8 & $(7.62)$ & 1.03 & $0.95-1.12$ & 0.47 \\
\hline Number of prenatal counselling's mean, (SD) & 2.6 & $(1.98)$ & 1.7 & $(2.03)$ & 1.23 & $1.09-1.38$ & 0.00 \\
\hline $\begin{array}{l}\text { Number of prenatal counselling's in 1st trimester, } \\
\text { mean, (SD) }\end{array}$ & 0.21 & (1.23) & 0.18 & $(0.93)$ & 1.04 & $0.84-1.29$ & 0.73 \\
\hline $\begin{array}{l}\text { Number of prenatal counselling's in } 2 \text { nd trimester, } \\
\text { mean, (SD) }\end{array}$ & 0.96 & $(1.92)$ & 0.80 & $(1.80)$ & 1.05 & $0.93-1.19$ & 0.44 \\
\hline $\begin{array}{l}\text { Number of prenatal counselling's in 3rd trimester, } \\
\text { mean, (SD) }\end{array}$ & 2.24 & $(1.79)$ & 1.36 & $(1.66)$ & 1.33 & $1.16-1.53$ & 0.00 \\
\hline \multicolumn{8}{|l|}{ Counselling at admission, $\mathrm{n} \%$} \\
\hline No & 29 & 26.4 & 142 & 69.27 & \multicolumn{2}{|c|}{ (reference) } & \\
\hline Yes & 81 & 73.6 & 63 & 30.73 & 6.30 & $3.75-10.56$ & 0.00 \\
\hline \multicolumn{8}{|l|}{$\begin{array}{l}\text { Counselling at admission ONLY } \\
\text { (no prenatal counselling), } \mathrm{n} \%\end{array}$} \\
\hline No & 102 & 92.7 & 191 & 93.17 & \multicolumn{2}{|c|}{ (reference) } & \\
\hline Yes & 8 & 7.3 & 14 & 6.83 & 1.07 & $0.43-2.64$ & 0.88 \\
\hline $\begin{array}{l}\text { Provider type for 1st counselling (among those with any } \\
\text { counselling) } n \%\end{array}$ & \multicolumn{2}{|c|}{$(\mathrm{n}=93)$} & \multicolumn{2}{|c|}{$(n=132)$} & & & \\
\hline Resident & 35 & 37.6 & 31 & 23.5 & \multicolumn{2}{|c|}{ (reference) } & \\
\hline Attending/Fellow & 43 & 46.2 & 57 & 43.2 & 0.67 & $0.36-1.25$ & 0.21 \\
\hline Midwife & 5 & 5.4 & 27 & 20.5 & 0.16 & $0.06-0.48$ & 0.00 \\
\hline Nurse Practitioner/Other & 10 & 10.8 & 17 & 12.9 & 0.52 & $0.21-1.31$ & 0.16 \\
\hline
\end{tabular}

*Odds ratio, 95\% confidence interval (CI) and p-value results from unadjusted logistic regression predicting IPP IUD placement. "Prenatal" counselling refers to counselling at an outpatient antenatal visit. Counselling at admission refers to counselling at hospital admission. 
Table 3. Models of adjusted* effects of characteristics of contraceptive counselling on receiving immediate postpartum (IPP) intrauterine device (IUD) placement

\begin{tabular}{|c|c|c|c|c|c|c|c|c|c|c|c|c|}
\hline \multirow[b]{2}{*}{ Characteristic } & \multicolumn{3}{|c|}{ Model 1} & \multicolumn{3}{|c|}{ Model 2} & \multicolumn{3}{|c|}{ Model 3} & \multicolumn{3}{|c|}{ Model 4} \\
\hline & OR & $95 \%$ CI & p-value & OR & $95 \% \mathrm{CI}$ & p-value & OR & $95 \% \mathrm{CI}$ & p-value & OR & $95 \% \mathrm{CI}$ & p-value \\
\hline $\begin{array}{l}\text { Number of prenatal } \\
\text { counselling sessions }\end{array}$ & 1.24 & $1.09-1.41$ & 0.001 & & & & & & & & & \\
\hline \multicolumn{4}{|c|}{ Number of prenatal counselling sessions in 1st trimester } & 0.97 & $0.76-1.24$ & 0.82 & & & & & & \\
\hline \multicolumn{4}{|c|}{ Number of prenatal counselling sessions in 2nd trimester } & 0.91 & $0.78-1.06$ & 0.24 & & & & & & \\
\hline \multicolumn{4}{|c|}{ Number of prenatal counselling sessions in 3rd trimester } & 1.43 & $1.21-1.70$ & 0.00 & 1.21 & $1.02-1.43$ & 0.03 & & & \\
\hline \multicolumn{13}{|c|}{ Number of prenatal counselling sessions in 3rd trimester } \\
\hline 0 & & & & & & & & & & \multicolumn{2}{|c|}{ (reference) } & \\
\hline 1 & & & & & & & & & & 1.91 & $0.86-4.27$ & 0.11 \\
\hline 2 & & & & & & & & & & 2.26 & $0.96-5.31$ & 0.06 \\
\hline 3 & & & & & & & & & & 6.01 & $2.20-16.41$ & 0.00 \\
\hline $4+$ & & & & & & & & & & 2.36 & $0.93-5.98$ & 0.07 \\
\hline \multicolumn{13}{|c|}{ Counselling at admission } \\
\hline No & & & & & & & \multicolumn{2}{|c|}{ (reference) } & & \multicolumn{2}{|c|}{ (reference) } & \\
\hline Yes & & & & & & & 5.10 & $2.01-9.71$ & 0.00 & 5.37 & $2.91-9.92$ & 0.00 \\
\hline
\end{tabular}

Table 4. Unadjusted and adjusted* effects of provider type at first contraceptive counselling on receiving immediate postpartum (IPP) intrauterine device (IUD) placement, among patients with any counselling documented

\begin{tabular}{|c|c|c|c|c|c|c|c|c|c|}
\hline \multirow{3}{*}{$\begin{array}{l}\text { Characteristic } \\
\text { Provider type for 1st counselling (among } \\
\text { those with any counselling) }\end{array}$} & \multirow{2}{*}{\multicolumn{2}{|c|}{$\begin{array}{c}\text { IPP IUD }(\mathbf{n}=93) \\
\text { Case }\end{array}$}} & \multirow{2}{*}{\multicolumn{2}{|c|}{$\begin{array}{c}\text { Non-IPP-IUD }(\mathrm{n}=132) \\
\text { Control }\end{array}$}} & \multirow{3}{*}{ Mean } & \multirow{3}{*}{ SD } & & & \multirow{3}{*}{ p-value } \\
\hline & & & & & & & OR & $95 \%$ CI & \\
\hline & $\mathbf{n}$ & $\%$ & $\mathbf{n}$ & $\%$ & & & \multicolumn{2}{|r|}{ Unadjusted } & \\
\hline Resident & 35 & 37.6 & 31 & 23.5 & 3.8 & 2.23 & \multicolumn{2}{|c|}{ (reference) } & \\
\hline Attending/Fellow & 43 & 46.2 & 57 & 43.2 & 2.5 & 168 & 0.67 & $0.36-1.25$ & 0.21 \\
\hline Midwife & 5 & 5.4 & 27 & 20.5 & 2.5 & 1.70 & 0.16 & $0.06-0.48$ & 0.00 \\
\hline Nurse Practitioner/Other & 10 & 10.8 & 17 & 12.9 & 2.1 & 1.15 & 0.52 & $0.21-1.31$ & 0.16 \\
\hline $\begin{array}{l}\text { Provider type for } 1 \text { st counselling (among } \\
\text { those with any counselling) }\end{array}$ & & & & & & & \multicolumn{3}{|c|}{ Adjusted* } \\
\hline Resident & & & & & & & \multicolumn{2}{|c|}{ (reference) } & \\
\hline Attending/Fellow & & & & & & & 0.76 & $0.35-1.63$ & 0.52 \\
\hline Midwife & & & & & & & 0.45 & $0.12-1.68$ & 0.22 \\
\hline Nurse Practitioner/Other & & & & & & & 0.63 & $0.21-1.86$ & 0.30 \\
\hline
\end{tabular}

*Logistic regression models predicting IPP IUD placement adjusting for gestational age at delivery, maternal age at delivery, gravidity, parity (living), prior TAB, prior SAB, delivery method, race/ethnicity, delivery year, number of 3rd trimester counselling's documented, and documented counselling on hospital admission.

\section{Discussion}

In our study, $15 \%$ of cases and $36 \%$ of controls had no documentation that prenatal contraceptive counselling was offered or given. This is out of line with professional society recommendations and not consistent with principles of reproductive health and autonomy. Even at major academic medical centres, continuous quality improvement appears warranted.

A higher number of prenatal counselling sessions was more closely associated with IPP IUD use than the timing of initiation of such counselling. Particularly, those who received an IPP IUD were significantly more likely to have three or more counselling sessions clustered during the third trimester than those who had two or fewer third trimester sessions, any number of first or second trimester sessions, or no sessions at all. When accompanied by outpatient prenatal counselling, those who received counselling at hospital admission were five times more likely to receive an IPP IUD.

Data from the Pregnancy Risk Assessment Monitoring System (PRAMS) indicates that prenatal counselling is associated with twice the rate of utilization of effective postpartum methods and an increased likelihood of using postpartum LARC at two months, but this data did not specifically examine IPP IUD use relative to other methods $[12,13]$. Based on our study data and given time constraints during prenatal visits, it may be reasonable to wait until the third trimester to offer counselling regarding IPP IUDs. Providers should not wait until hospital admission to offer contraceptive counselling, especially given limited time and stressful circumstances often associated with hospital admission. However, while this study included live deliveries of all gestational ages, waiting to counsel until the third trimester may limit counselling opportunities for patients who deliver preterm. Counselling, when offered and accepted, should be comprehensive, based on the patient's desires and preferences, and rooted in principles of reproductive justice which acknowledges historical reproductive injustices, avoids coercion, and promotes autonomy [14].

Provider type, at least as documented for the first counselling session, did not differentially affect uptake of IPP IUD. Preferential counselling in favour of certain methods based on provider preference or bias would have raised concerns for contraceptive coercion, particularly as we were unable to determine if conversations were patient or provider driven. Providers should offer all medically appropriate options and be respectful of patients who decline counselling while still documenting that such counselling was offered.

Strengths include the focus on immediate postpartum IUD uptake rather than global postpartum use. Though the content of contraceptive counselling was not standardized in our sample, this reflects clinical 
reality. Given that all approved contraceptive methods were free to Medicaid patients, we were able to evaluate the effects of counselling on uptake without cost as a barrier. Limitations include documentation and small sample size. Providers may have copied information from a previous note, thus falsely increasing the number of times counselling occurred. Not all discussions may have been documented; although midwives were found to provide less counselling, this may be the result of lack of documentation. While our patient population is diverse, our sample size is relatively small $(n=315)$ and limited to one midwestern city, limiting generalizability. The small sample size may also have impacted the power of our study to identify which factors were significant. Cost was not a barrier to method choice in our sample, which may limit generalizability. Additionally, we only examined the impact of variable counselling practices on IPP IUDs. We chose to focus on counselling related to IPP IUDs given that this method is relatively new, understudied, and not widely disseminated in clinical practice. Further study is required to determine how different counselling patterns may impact postpartum use of other or no method.

From a reproductive justice framework, all individuals (cases and controls) may be seen as having a successful outcome if they were offered counselling on the full range of appropriate options and were able to access their desired method without barriers. It is not possible for us to comment on these more broad and vital outcomes given limitations of the current retrospective methodology.

\section{Acknowledgement} USA.

Taylor Potter, BS Candidate, Spelman College, Atlanta, Georgia,

\section{Funding information}

This research was supported in part by funding from the Wisconsin Medical Society through a medical student fellowship grant for summer living expenses for Dr. Sullender and in part by the Jeanne Bissell Endowed Professorship in Reproductive Justice for Dr. Wautlet.

\section{References}

1. White K, Teal SB, Potter JE (2015) Contraception after delivery and short interpregnancy intervals among women in the United States. Obstet Gynecol 125: 1471-1477. [Crossref]

2. Conde-Agudelo A, Rosas-Bermudez A, Kafurty-Goeta AC (2007) Effects of birth spacing on maternal health: a systematic review. Ob J Obstet Gynecol 196: 297-308. [Crossref]

3. Conde-Agudela A, Rosas-Bermudez A, Kafury-Goeta AC (2006) Birth spacing and risk of adverse perinatal outcomes: a meta-analysis. JAMA 295: 1809-1823. [Crossref]

4. Potter JE, Hubert C, Stevenson AJ, Hopkins K, Aiken ARA, et al. (2016) Barriers to Postpartum Contraception in Texas and Pregnancy Within 2 Years of Delivery. Obstet Gynecol 127: 289-296. [Crossref]

5. Aiken AR, Borrero S, Callegari LS, Dehlendorf C (2016) Rethinking the Pregnancy Planning Paradigm: Unintended Conceptions or Unrepresentative Concepts? Perspect Sex Reprod Health 48: 147-151.

6. Levi EE, Stuart GS, Zerden ML, Garrett JM, Bryant AG (2015) Intrauterine Device Placement During Cesarean Delivery and Continued Use 6 Months Postpartum: A Randomized Controlled Trial. Obstet Gynecol 126: 5-11. [Crossref]

7. Dahlke JD, Terpstra ER, Ramseyer AM, Busch JM, Rieg T, et al. (2011) Postpartum insertion of levonorgestrel--intrauterine system at three time periods: a prospective randomized pilot study. Contraception 84: 244-248. [Crossref]

8. Chen BA, Reeves MF, Hayes JL, Hohmann HL, Perriera LK, et al. (2010) Postplacenta or Delayed Insertion of the Levonorgestrel Intrauterine Device After Vaginal Delivery: A Randomized Controlled Trial. Obstet Gynecol 116: 1079-1087. [Crossref]

9. Whitaker AK, Chen BA (2017) Society of Family Planning Guidelines: Postplacental insertion of intrauterine devices. Contraception 97: 2-13. [Crossref]

10. Committee on Obstetric Practice (2016) Immediate Postpartum Long-Acting Reversible Contraception. American College of Obstetricians and Gynecologists.

11. Coleman-Minahan K, Aiken ARA, Potter JE (2017) Prevalence and Predictors of Prenatal and Postpartum Contraceptive Counseling in Two Texas Cities. Womens Health Issues 27: 707-714. [Crossref]

12. Hernandez LE, Sappenfield WM, Goodman D, Pooler J (2012) Is effective contraceptive use conceived prenatally in Florida? The association between prenatal contraceptive counseling and postpartum contraceptive use. Matern Child Health J 16: 423-429. [Crossref]

13. Zapata LB, Murtaza S, Whiteman MK, Jamieson DJ, Robbins CL, et al. (2015) Contraceptive counseling and postpartum contraceptive use. Am J Obstet Gynecol 212 171.e171-178. [Crossref]

14. Kaitz M, Mankuta D, Mankuta L (2019) Long-acting reversible contraception: A route to reproductive justice or injustice. Infant Ment Health J 40: 673-689. [Crossref]

Copyright: (C2020 Sullender RT. This is an open-access article distributed under the terms of the Creative Commons Attribution License, which permits unrestricted use, distribution, and reproduction in any medium, provided the original author and source are credited. 